\title{
Cerebral Blood Flow
}

National Cancer Institute

\section{Source}

National Cancer Institute. Cerebral Blood Flow. NCI Thesaurus. Code C94869.

Perfusion of blood through the cerebrum. 